\title{
A Review on Sustainable Transportation
}

\section{Gomasa Ramesh}

\begin{abstract}
Any mode of transportation that is green and has a low environmental effect is considered sustainable transportation. It's all about juggling our immediate and longterm interests when it comes to transportation. Rolling, riding, transit, carpooling, car sharing, and electric cars are also examples of urban mobility. Transportation is the single greatest cause of air pollution and greenhouse gas emissions. Everyone can further reduce their adverse consequences by opting for efficient transportation instead of driving a vehicle. Transportation emits around a quarter of all pollution, according to the Environmental Protection Agency. The typical automobile emits $4,720 \mathrm{~kg}$ of $\mathrm{CO}_{2}, 186.6$ kilograms of $\mathrm{CO}, 28$ kilograms of $V_{O C}$, and 25.6 kilograms of $\mathrm{NO}_{\mathrm{x}}$
\end{abstract}

Keywords: Sustainability, Transportation, Goals, Objectives.

\section{INTRODUCTION}

$T$ he term "sustainability" refers to more than just the production and pollution of a company. Usage, application, and post-use aspects all go through a life-cycle evaluation. Focusing on a single aspect, such as energy efficiency, is less critical than cradle-to-cradle architecture. According to the Center for Sustainable Transportation, a sustainable transportation scheme allows people and cities to meet their access needs safely and equity inside and through generations. It is accessible, runs smoothly, provides various modes of transportation, and contributes to a thriving economy. Restricts carbon and minimizes nonrenewable resource use, limits renewable resource use to the appropriate yield standard, reuses and recycles their materials, and reduces land use and noise generation. The word "sustainable transportation" was coined as a conceptual extension to "sustainable growth," It refers to forms of transportation and transportation planning processes that are in line with broader environmental considerations. Sustainable transportation and the similar concepts of sustainable transportation and sustainable mobility have a wide range of meanings and sustainable transportation schemes.

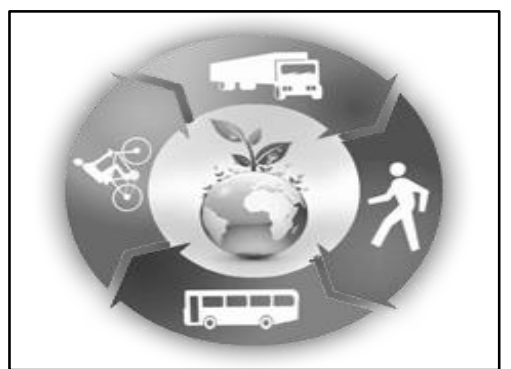

Fig.1 Sustainable Transportation

\footnotetext{
Manuscript received on 01 May 2021 | Revised Manuscript received on 12 May 2021 | Manuscript Accepted on 15 November 2021 | Manuscript published on 30 November 2021. * Correspondence Author

Gomasa Ramesh*, Department of Civil and Structural Engineering Vaagdevi College of Engineering, Warangal, 506005, Telangana, India EMail:rameshgomasa1@gmail.com

(c) The Authors. Published by Lattice Science Publication (LSP). This is an open access article under the CC-BY-NC-ND license (http://creativecommons.org/licenses/by-nc-nd/4.0/)
}

\section{OBJECTIVES}

Leaving your car at home and opting for more environmentally friendly forms of transport would help both you and the city. Among them are:

- Congestion was reduced.

- $\quad$ Reduced air quality and asthma complications

- $\mathrm{CO}_{2}$ levels are being reduced.

- $\quad$ Reduced reliance on nonrenewable forms of energy

- Transport expenses are reduced.

- Physical activity levels have increased.

- Social interaction is increasing.

- A thriving economy and support for local businesses

- Improved quality of life and healthier lifestyles

\section{METHODOLOGY}

Components of a Long-Term Transportation System

- Sustainable transportation necessitates four main features. Following are the main features of the transportation system.

\section{A City-Wide Transportation Strategy}

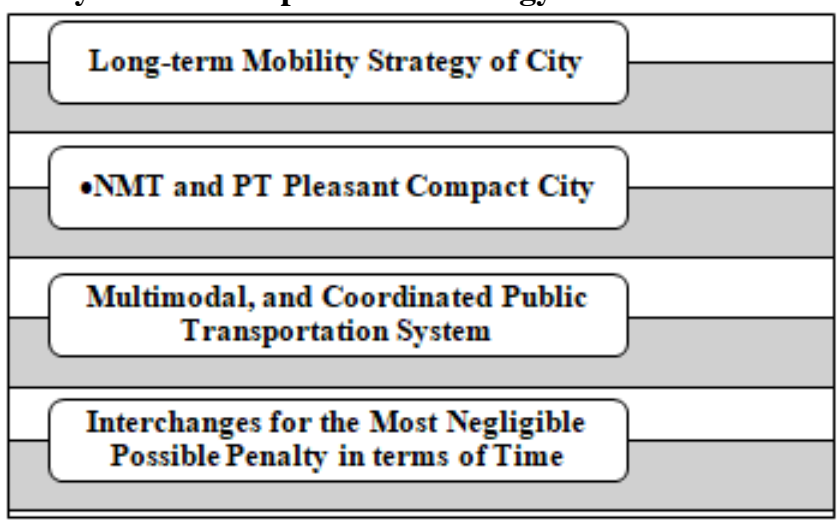

- There are almost 20 elements of urban transportation that can be divided into three categories: types of transportation, utilities, and associated events. Buses, paratransit, automobiles, taxis, goods vehicles, NMT, and personal vehicles are among the modes of transportation. Related activities include traffic calming, compliance, driver instruction, registration, and transportation demand control initiatives. Infrastructure incorporates highways, intersections, bridges, by-passes, airports, interchanges, parking, pedestrian/bicycle facilities, and bus access systems, with designated routes and terminals for water and rail travel. To get the most out of these functions, they must be designed and introduced.

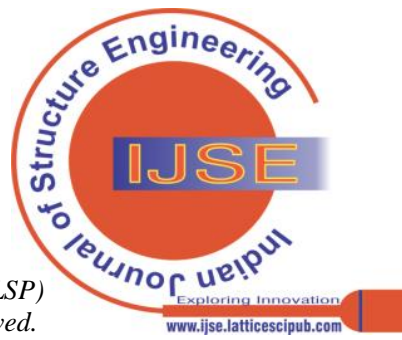




\section{Small Town}

NMT and PT are also sustainable means of transportation, and a small city that promotes both is superior to sprawl. A mass transportation infrastructure accessible across the city A commuter must finish his ride on public transportation. As a result, a city-wide PT framework is needed. A commuter's car is often referred to as PT due to concerns about the final mile. As a result, physical therapy should be planned "door to door." Pedestrians and riders should be able to get to stations and stops quickly and easily. This will increase the use of PT while also enhancing its financial viability and long-term viability. Interchanges for the most negligible possible penalty in terms of time Point-to-point transportation is generally prohibited in urban agglomerations. As a result, the majority of riders would have to switch forms of transportation. Interchanges can enable commuters to do so in a comfortable and time-efficient manner, resulting in smooth riding. It's just as necessary to plan a multimodal PT scheme as it is to design functional interchanges.

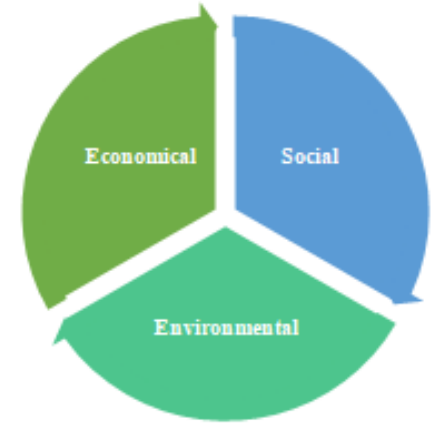

Fig.2 Goals of Sustainability

Sustainable transportation is a diverse transportation category that encompasses social, financial, and climate impacts. When assessing sustainability, consider the automobiles used for road, water, air transportation, and the energy supply and facilities. The efficacy and reliability of transportation systems and the system's environmental and climate effects are used to determine transportation sustainability. People quickly take advantage of the improved mobility provided by transportation networks, which serve to provide social and economic links. Traditional transportation planning focuses on increasing mobility, particularly for vehicles, but it may overlook broader consequences.

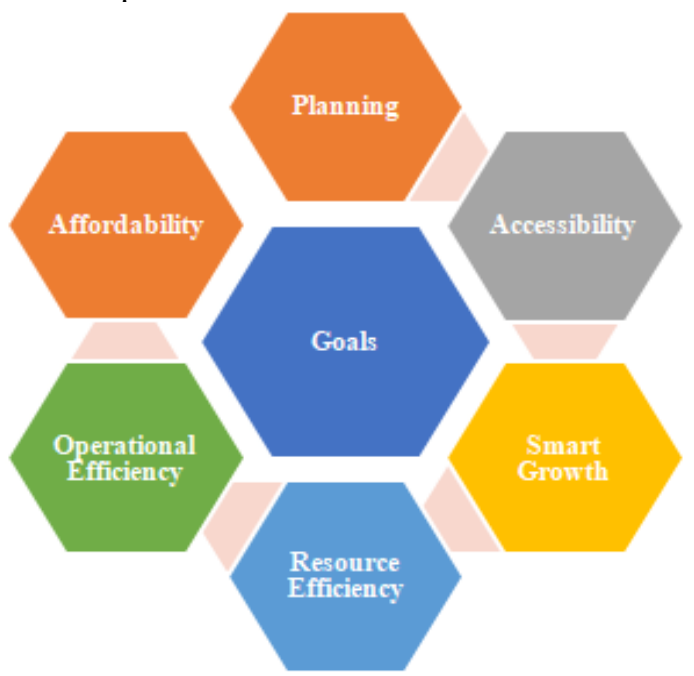

Fig.3 Goals of Sustainability Transportation
Communities that effectively ensure the long-term stability of their transit networks do so as part of a more significant commitment to improving their communities' prosperity, livability, and sustainability. Allows people, businesses, and society's critical access and growth need to be addressed securely and in a way that is compatible with human and ecosystem well-being while still promoting justice within and across generations. It is cost-effective, runs equally and effectively, provides various transportation options, and promotes a sustainable environment and healthy economic growth. Unintended effects have been attributed to drastic declines in public transportation, biking, and commuting in cities with overbuilt roadways. Streets lost their "life" in many ways. Stores, colleges, government centers, and libraries relocated from significant towns. People who did not relocate to the outskirts saw a significant reduction in public space and facilities quality.

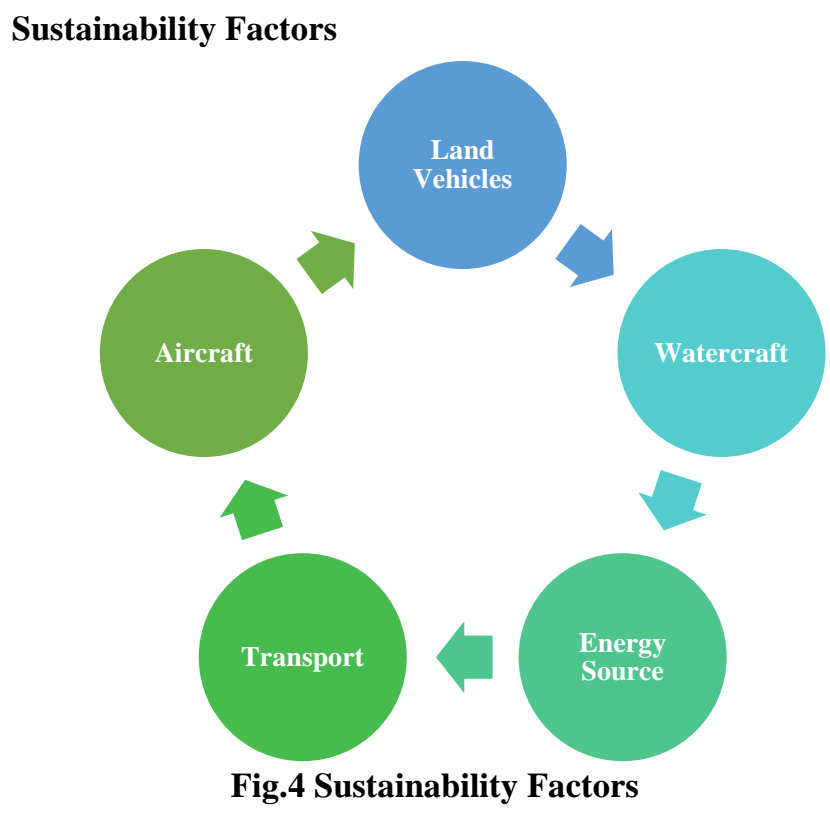

Individuals can fulfill their basic needs more easily and in a way that is consistent with human and ecosystem wellbeing and equity within and through generations through a sustainable transportation model. It is easily available, operates well, offers various transportation choices, and leads to a healthy economy. Limit's pollution and waste to the potential of the earth to consume them minimizes nonrenewable resource use, limits renewable resource use to acceptable yield levels, reuses and recycles their materials, and reduces land use and noise generation. Sustainability stresses the interconnectedness of human operations, necessitating concerted planning through markets, groups, and jurisdictions. It broadens the scope of a planning process's goals, consequences, and choices, ensuring that short-term choices are made in line with long-term strategic objectives. Since transportation choices influence citizens in several ways, sustainable transportation design considers various goals and impacts.

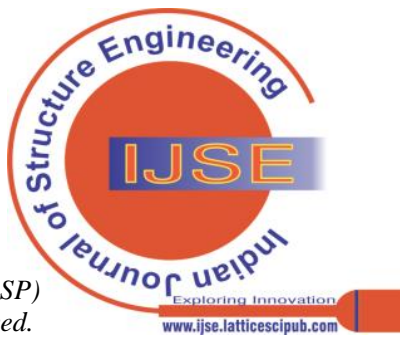


Several transportation planning goals help to achieve sustainability: Diverse modes of transportation Travelers may select from a variety of modes, locations, and pricing choices, with a focus on those that are economical, safe, and reliable, as well as those that fit non-drivers' incorporation of systems. Pedestrian and bike links to buses and integrated transportation and land use development are both wellintegrated elements of the transportation infrastructure. Cost-effectiveness Transport programs make consumer products, services, and events more available for lowincome families, allowing them to invest less than $20 \%$ of their income on them. Performance in the use of resources, both energy, and land. Policies promote energy and land efficiency. Access to land for the use of smart growth. To increase land

use accessibility and transportation alternatives, policies encourage small, mixed, linked, multimodal construction. Performance in operations to reduce expenses and improve customer efficiency, transportation agencies, service suppliers, and services are well-managed. Planning that is thorough and inclusive. Comprehensive and considers both significant goals, effects, and options, collaborative and decision-making are organized by various markets, jurisdictions, and agencies, and inclusive planning is all characteristics of good planning, and all affected people can participate. Concurrently schedule transportation and land use to account for the impact of land use on transportation demand and availability and the impact of transportation networks on land use demand and trends. Promote supportive land use shape and design of transportation plan policies, e.g., compact, mixed-use, pedestrian-friendly. Recognize how transit services will aid in the achievement of environmental priorities and lend support to the programmer's strategic objectives. In the technical assessment of potential land use or transit scenarios, use environmental parameters emissions of greenhouse gases and other atmospheric pollution, nonrenewable resource consumption, etc. Recognize how transit services will aid in achieving social objectives and lend support to the programmer's strategic priorities. Develop policies to increase mobility for disabled and low-income people, new refugees, teenagers, and the elderly, such as reducing travel requirements and expanding public transportation. Develop policies to improve accessibility and independence for people with disabilities, such as removing barriers to public transportation and pedestrian facilities. Recognize how transit services will aid economic growth and lend support to the plan's strategic goals. Develop policies to promote successful and productive products flow to and from significant gateways such as ports, airports, and border crossings, and main corridors. Create a robust planning plan that includes a mission, priorities, and other components and specific connections to other group goals. Consider several scenarios for land use and transit schemes and weigh in on the conditions and consequences. Identify ways to increase biking, hiking, public transportation, ridesharing, and teleworking. Develop plans for improving the long-term viability of transit operations. Develop policies to allow automobiles to be more environmentally friendly, e.g., incident management, signal optimization, traveler information. Develop parking efficiency plans to help you meet your transportation targets. As a supplement to controlling transportation supply, place a strategic focus on transportation demand management (TDM). Build plans for various TDM methods, such as construction permits, pricing, rewards, and outreach. Identify solutions for maximizing existing infrastructure's multimodal potential, e.g., transit priority, access management. Develop solutions for dealing with both persistent and nonrecurring traffic congestion. Develop transportation resources management plans, e.g., maintenance, repair, rehabilitation, renewal.

\section{IV.RESULTS AND DISCUSSION}

Determine a long-term implementation plan that explains core infrastructure, operation, initiative, and policy goals and is focused on expected results. Determine a short-term transition plan that outlines early steps that can help you gain traction and pave the groundwork for long-term progress. Determine potential transit sales and capital and operational expenses, including the cost of programs, services, fleets, facility construction, and maintenance. Make a list of alternatives for filling funding holes. Determine principles for healthy consumption to get the most out of the money you have. Emphasize the importance of a successful assessment program for tracking progress against preparation objectives. Develop a success assessment system linked to the structural framework of the strategy and track results, results, and external factors. Determine a reporting strategy for efficiently communicating the outcomes of success assessment. Involve the public in the transit planning phase, and find opportunities to improve potential program and project execution through public participation. As an expansion to the strategy, identify a mechanism for routine changes to the development schedule. The Indian government has taken significant measures to encourage sustainable transportation.

National Urban Transport Policy

Global Environment Facility

Improving the Structural Framework $\checkmark$

\section{Enhancing the Efficiency of Oils}

Raising the Rigour of Emission Standards 5

\section{Mass Rapid Transit Systems}

Launching a Large-Scale Capacity-Building

- In 2006, the National Urban Transport Policy (NUTP) was finalized and released.

- $\quad$ Started demonstration programs in collaboration with the Global Environment Facility (GEF).

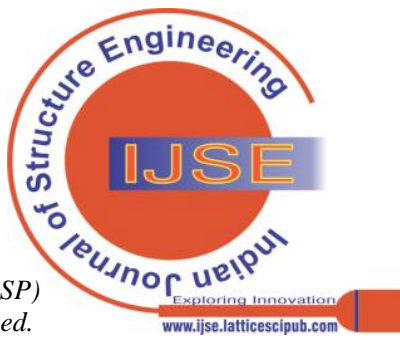


- Improving the structural framework four and launching a large-scale capacity-building initiative

- Encouragement of improvements to all road and railbased mass rapid transit (MRT) systems.

- Raising the rigor of emission standards and enhancing the efficiency of oils.

\section{CONCLUSION}

- India's urban population has risen dramatically and is expected to continue to rise. In terms of the percentage of the overall population, urbanization has increased from 18 percent in the nineteenth century to 30 percent in the twentieth century.

- $\quad$ It is projected to reach about 38 percent by 2021. As a result, the number and scale of cities have grown dramatically. While conditions vary significantly between cities in India, specific fundamental patterns that influence transportation demand, such as significant increases in urban population, household incomes, and industrial and commercial activities, are consistent.

- These reforms have put a strain on urban transportation networks, which several Indian cities have been unable to accommodate. The development of an urban transportation plan that is both realistic and inclusive is urgently needed.

- Urban transportation growth on a safe road in cities is the most pressing need of the hour; local contamination is a health problem, and GHG emissions are a global concern. The current urban transport landscape in India, in general, is very unsustainable; the usage of automobiles and twowheelers is on the rise, and public transportation is in short supply, and PT is inadequate, while walking and cycling are becoming less popular.

\section{Funding}

This study has not received any external funding.

\section{Conflict Of Interest}

The author declares that there are no conflicts of interest.

\section{REFERENCES}

1. Harun 2018 et al. "Sustainable Transportation."

2. Gudmundsson 2016 et al. "Sustainable Transportation", Springer Series. [CrossRef]

3. Nagurney, A. (2000). Sustainable transportation networks. Books.

4. Steg, L., \& Gifford, R. (2005). Sustainable transportation and quality of life. Journal of transport geography, 13(1), 59-69. [CrossRef]

5. Haghshenas, H., \& Vaziri, M. (2012). Urban sustainable transportation indicators for global comparison. Ecological Indicators, 15(1), 115-121. [CrossRef]

6. Naganathan, H., \& Chong, W. K. (2017). Evaluation of state sustainable transportation performances (SSTP) using sustainable indicators. Sustainable cities and society, 35, 799-815. [CrossRef]

7. Gomasa Ramesh, Dharna Ramya, Mandala Sheshu Kumar; "Health Monitoring of Structures by Using Non-Destructive Testing Methods", International Journal of Advances in Engineering and Management (IJAEM) Volume 2, Issue 2, pp: 652-654, DOI:10.35629/5252-45122323

8. Gomasa Ramesh, Doddipati Srinath, Mandala Sheshu Kumar; "Earthquake Resistant of RCC Structures" Published in International Journal of Trend in Scientific Research and Development (ijtsrd), ISSN: 2456-6470, Volume-4, Issue-5, August 2020, pp.808-811.

9. Gomasa Ramesh, Doddipati Srinath, Mandala Sheshu Kumar, "Importance of Dynamic Analysis for RCC Structures," International
Journal for Modern Trends in Science and Technology, 6(8): 271-276, 2020, DOI:10.46501/IJMTST060844 [CrossRef]

10. Gomasa Ramesh, D Srinath, "Repair, rehabilitation and retrofitting of reinforced concrete structures by using non-destructive testing methods," March 2021, Materials Today: Proceedings, DOI: 10.1016/j.matpr.2021.02.778 [CrossRef]

11. D Srinath, G Ramesh, "Mechanical properties of sustainable concrete by using RHA and hydrated lime," March 2021, Materials Today: Proceedings, DOI: 10.1016/j.matpr.2021.02.785 [CrossRef]

12. Gomasa Ramesh, "Study on Mechanical Properties of Polyurethane Foam Concrete", Indian Journal of Structure Engineering (IJSE) Volume-1 Issue-1, May 2021, pp:1-3, DOI:10.35940/ijse.B8005.051121. [CrossRef]

13. Gomasa Ramesh, "Importance and Applications of GIS in Engineering", Indian Journal of Structure Engineering (IJSE) Volume-1 Issue-1, May 2021, pp:4-8, DOI:10.35940/ijse.B8005.051121. [CrossRef]

14. Gomasa Ramesh, "Transparent Concrete: A Review", Indian Journal of Structure Engineering (IJSE) Volume-1 Issue-1, May 2021, pp:4-8, DOI:10.35940/ijse.B8005.051121. [CrossRef]

15. Gomasa Ramesh, "Pervious Concrete: A Review", Indian Journal of Structure Engineering (IJSE) Volume-1 Issue-1, May 2021, pp:4-8, DOI:10.35940/ijse.B8005.051121. [CrossRef]

16. Gomasa Ramesh, "Low Carbon Buildings for Sustainable Constructions", Indian Journal of Structure Engineering (IJSE) Volume-1 Issue-2, November 2021, PP:1-4 DOI:10.35940/ijse.B8003.111221. [CrossRef]

17. Gomasa Ramesh, "Geopolymer Concrete: A Review", Indian Journal of Structure Engineering (IJSE) Volume-1 Issue-2, November 2021 PP:5-8, DOI:10.35940/ijse.A1302.111221. [CrossRef]

18. Gomasa Ramesh, "Self-Compacting Concrete: A Review", Indian Journal of Structure Engineering (IJSE) Volume-1 Issue-2, November 2021, PP:9-12, DOI:10.35940/ijse.A1303.111221. [CrossRef]

19. Gomasa Ramesh, "Slope and Landslide Stabilization: A Review", Indian Journal of Structure Engineering (IJSE) Volume-1 Issue-2, November 2021, PP:13-16, DOI:10.35940/ijse.A1304.111221. [CrossRef]

\section{AUTHORS PROFILE}

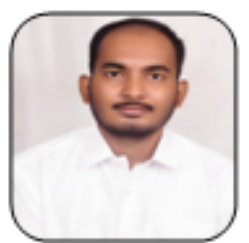

Mr. Gomasa Ramesh, B. Tech Civil Engineering M.Tech Structural Engineering, Vaagdevi College of Engineering, Warangal, 506005, Telangana, India. Presented and participated in various International conferences and National Conferences and received Best Paper Awards for some Papers and received Best Young Researcher Award for 2020. Published more than 20 Research Papers in International Peer-Reviewed UGC Journals. Member of various Professional Bodies American Society of Civil Engineers, Structural Engineering Institute, Institute of Structural Engineering, American Concrete Institute and American Society of Testing Materials etc.

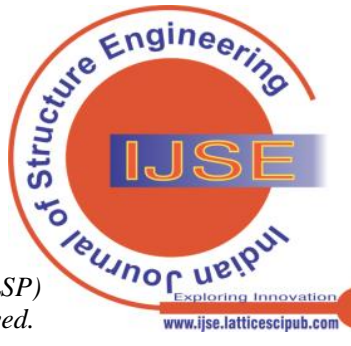

